\title{
Sobre diversidades e regionalidades: a ascensão da Quarta Onda da ficção científica brasileira
}

\author{
On Diversities and Regionalities: The Rise of the \\ Fourth Wave in Brazilian Science Fiction
}

Alexander Meireles da Silva ${ }^{1}$

DOI: $10.19177 /$ memorare.v8e1202161-80

\begin{abstract}
Resumo: Tema recorrente nos estudos da ficção científica brasileira, o conceito das ondas vem sendo empregado pela área acadêmica como uma forma de entendimento da periodização desta expressão da literatura fantástica desde fins do século 20. Neste contexto, desde o início do século 21, em coexistência com as duas ondas anteriores, acredita-se que a ficção científica nacional está vivenciando sua Terceira Onda. Todavia, como será demonstrado por meio das características dessas ondas, este artigo defende a hipótese de que desde meados da década de 2010, a ficção científica nacional já está apresentando elementos do que pode ser chamada da Quarta Onda. Entre outros pontos, esta Quarta Onda pode ser entendida pela afirmação e celebração das diversidades socioculturais e regionais do Brasil, formalizada pela maior presença na cena literária de escritores e escritoras negras ligadas ao afrofuturismo e a ascensão de movimentos como o amazofuturismo e o sertãopunk.

Palavras-chave: Ficção Científica Brasileira. Amazofuturismo. Sertãopunk
\end{abstract}

\begin{abstract}
A recurrent theme in Brazilian Science Fiction studies, the concept of waves has been used by academic area as a way of understanding the periodization of this expression of Fantastic Literature since late-twentieth century. In this context, since the beginning of the twenty-first century, and in coexistence with the two previous waves, it is believed Brazilian Science Fiction is experiencing its Third Wave. However, as it will be demonstrated through the characteristics of these waves, this article defends the hypothesis that since mid-2010s, Brazilian science Fiction is already presenting elements of what can be called the Fourth Wave of this strand in Fantastic Literature. Among other points, this Fourth Wave may be understood by the affirmation and celebration of Brazilian sociocultural and regional diversities, formalized both by a deeper presence in literary scene of black writers linked to Afrofuturism and by the rise of moviments such as Amazofuturism and Sertãopunk.
\end{abstract}

Keywords: Brazilian Science Fiction. Amazofuturism. Sertãopunk

1 Universidade Federal de Catalão (UFCat).E-mail: prof.alexms@gmail.com 


\section{Introdução: Como uma onda no mar}

Primeira Onda, Segunda Onda, Terceira Onda.... O conceito de ondas da ficção científica ${ }^{2}$ brasileira vem fazendo parte dos estudos e debates acadêmicos sobre a evolução e manifestações desta vertente da literatura fantástica no Brasil desde fins da década de 1970. 0 início dessa tentativa de periodização da ficção científica em nosso país enquanto instrumento para a compreensão de seus nomes, motivos, estilos e características se deu em 1976, com a publicação da dissertação de mestrado intitulada Unique Motifs in Brazilian Science Fiction, de David Lincoln Dunbar. Para a realização de sua pesquisa sobre as características e temas da ficção científica desenvolvida no Brasil durante a década de 1960, em 1972 o pesquisador norteamericano empreendeu viagem até São Paulo afim de entrevistar escritores, escritoras, tradutores e editores da ficção científica nacional. Os nomes citados por ele, incluindo o próprio escritor André Carneiro, que possibilitou os contatos para as conversas, nos ajudam a compreender o processo de identificação do grupo que veio a ser considerado posteriormente como pertencente ao primeiro período da FC brasileira:

Com a ajuda de [André] Carneiro, eu tive o privilégio de entrevistar escritores reconhecidos como Rachel de Queiroz, Ruy Jungmann, Orígenes Lessa, Rubens Teixeira Scavone, Fausto Cunha (escritor-crítico), Moacir Lopes (escritor-editor), e Dinah Silveira de Queiroz. (Eu tive a sorte de encontrar o marido de Dinah, o senhor Castro Alves, Secretário de Assuntos Exteriores do Brasil.) Eu também visitei a residência e entrevistei Terezinha Monteiro Deutsch, filha do falecido Jerônymo Monteiro. (Ele é considerado por muitos como o "Pai" da Ficção Científica Brasileira.). (1976, p. iv, tradução do autor).

Outro escritor citado por David Lincoln Dunbar como participante das entrevistas foi o contista Nilson Martello. Da mesma forma, ainda segundo Dunbar, os escritores Ney Morais, Clóvis Garcia, e Walter Martins não puderam participar das entrevistas devido a problemas de saúde ou outros compromissos (1976, p. v). Completando os nomes buscados pelo norte-americano, destaque também para Gumercindo R. Dórea, "o maior e melhor editor de ficção científica no Brasil de acordo com André Carneiro; Jose Sanz, tradutor prolífico e divulgador da ficção científica; Benedicto Luz e Silva, escritor, crítico e editor." (1976, p. v). Como resultado de sua investigação, dentre outras observações, o pesquisador considerou que a produção literária brasileira da década de 1960 antecipou a proposta de renovação temática e estilística da FC observada na ficção científica da Inglaterra de fins da mesma década e que veio a ser conhecida como "New Wave" - A Nova Onda (1976, p. 34). Estabeleceu-se, assim, a ligação da primeira geração de escritores e escritoras da ficção científica nacional, enquanto gênero literário estabelecido, com a ideia de onda.

Cabe salientar de que este trabalho da delineação da produção literária da FC enquanto gênero no Brasil dos anos 60 e 70, com “a sugestão de que Carneiro, Scavone, Cunha, Dinah Silveira de Queiroz, e os outros escritores sejam vistos como iniciadores no campo" (DUNBAR,

2 O termo "Ficção Científica" poderá aparecer ao longo do texto identificado como "FC". 
1976, p. 137), já havia sido abordado brevemente pelo escritor André Carneiro em Introdução ao estudo da "Science Fiction" (1967) e pelo crítico Fausto Cunha em No mundo da ficção científica (1974). Na primeira obra, Carneiro dedicou o fim do quinto e último capítulo do seu estudo histórico-crítico para mencionar os escritores e escritoras nacionais de ficção científica da década de 60. Já no ensaio de título "A ficção científica no Brasil: um planeta quase desabitado", que abre o livro do crítico norte-americano L. David Allen, Fausto Cunha batizou os escritores e escritoras publicados pelo editor Gumercindo da Rocha Dórea de “Geração GRD” (1974, p. 11). Nos dois casos, portanto, existia a menção aos mesmos nomes que seriam objeto da investigação de David Lincoln Dunbar publicada em 1976.

O termo "Primeira Onda" ganhou a sua disseminação no início do século XXI com a publicação de Cosmos Latinos: An Anthology of Science Fiction from Latin America (2003). Editado por Andrea L. Bell e Yolanda Molina-Gavilán, esta antologia cobriu a produção de ficção científica da Espanha e dez países da América Latina no período de 1862 até os primeiros anos de 2000. Ao apresentar a estruturação do livro com base em sua proposta, as editoras citam que,

A maior seção desta antologia, é intitulada "A Primeira Onda: Os anos de 1960 até meados dos anos de 1980." Ela mostra quatorze histórias da Argentina, Brasil, Chile, Cuba. El Salvador, México, Peru, e Venezuela que exemplificam a primeira "era dourada" do gênero nas décadas de 1960 e 1970. (BELL; YOLANDA, 2003, p. 19)

Podemos especular que talvez a estipulação de um termo que traga "Primeira" em seu nome, levando inevitavelmente a reflexão sobre períodos subsequentes usando o mesmo, e simples, padrão ordinal tenha contribuído para a sedimentação do termo "Primeira Onda" em detrimento de, por exemplo, "Geração GRD”. Neste sentido, as transformações das décadas seguintes da ficção científica brasileira pós anos 70, levadas a cabo por escritores e escritoras em decorrência de fatores políticos, econômicos, tecnológicos e culturais, fomentaram a percepção do surgimento e disseminação de novas ondas.

Mas, em que período poderíamos dizer que a ficção científica brasileira se encontra neste início da terceira década do século XXI? Visando propor uma resposta para esta questão, este artigo defende a hipótese de que, desde meados da década de 2010, a FC em nosso país já está apresentando características do que pode ser chamada da Quarta Onda desta vertente da literatura fantástica. Entre outros elementos, esta Quarta Onda seria entendida pela afirmação e celebração das diversidades socioculturais e regionais do Brasil, formalizada pela maior presença na cena literária de escritoras e escritores negros e pertencentes a regiões do Brasil historicamente marginalizadas pelo eixo sul e sudeste de produção e divulgação literária. Essa nova realidade ganha corpo em movimentos como o afrofuturismo, o amazofuturismo e o sertãopunk. Todavia, para um melhor entendimento da configuração deste quadro, faz-se necessário antes determos o nosso olhar sobre o surgimento, evolução e características da Segunda e Terceira Ondas. Esta contextualização também possui o propósito de preencher lacunas nos estudos da ficção científica 
brasileira no que se refere ao processo de identificação e características das ondas dessa expressão da literatura fantástica em nossas letras.

\section{Olha a onda, olha a onda: reflexões sobre a Segunda Onda}

Em 2003, o uso pelo pesquisador e escritor Roberto de Sousa Causo do termo "Segunda Onda" em sua obra seminal para os estudos de FC no Brasil - Ficção Científica, Fantasia e Horror no Brasil: 1875-1950 (2003), evidenciou a disseminação do uso do termo "Onda" nos círculos de debates da ficção científica nacional. Como ele argumenta sobre o período dessa literatura entre os anos de 1980 e 2000: “A partir de 1982 deu-se início à Segunda Onda - ou a "Renascença da FC Brasileira" -, em torno do surgimento do Fandom Moderno. Novos escritores apareceram, novos estilos e tendências foram apresentados." (2003, p. 297-298).

Caracterizada pelo surgimento de revistas especializadas, fanzines e clubes de leitura organizados por escritores, escritoras e um pequeno, mas engajado público leitor, a Segunda Onda da ficção científica no Brasil se desenvolveu em um momento histórico-cultural de lenta redemocratização do país após o fim da Ditadura Militar, aumento da liberdade de expressão em veículos de comunicação, flexibilização dos costumes na sociedade e repetidas crises econômicas. Este quadro gerou o surgimento de novos desafios e possibilidades para toda uma geração. Como salienta a pesquisadora M. Elizabeth Ginway:

... em 1985, nós temos a publicação de Padrões de contato (1985), de Jorge Luiz Calife, o romance seminal da nova geração chamada Segunda Onda (tendo sido a Primeira Onda a geração GRD). [...] Em 1985, Calife se torna uma celebridade entre os fãs após receber o reconhecimento de ninguém menos que Arthur C. Clarke, que o agradeceu por fornecer a inspiração para a longamente esperada sequência de 2001: Uma Odisséia no Espaço (1968). (CAUSO; GINWAY, 2010, p. 23).

Contando com representantes como, dentre outros nomes, Roberto de Sousa Causo, Gerson Lodi-Ribeiro, Ivan Carlos Regina, Bráulio Tavares, José dos Santos Fernandes, Fábio Fernandes, Carlos Orsi, Finísia Fideli, Roberto Schima, Ivanir Calado, Ataíde Tartari, Marcello Simão Branco, Cesar Silva, Simone Saueressig, Claudia Dugim, Gilson Luis da Cunha, Luiz Felipe Vasquez e Octávio Aragão, foi na Segunda Onda que conseguiremos observar, pela primeira vez, as duas primeiras características das ondas da ficção científica brasileira: Primeiro, a existência de um manifesto ou posicionamento formal de pessoas identificadas com o momento literário em que elas estão inseridas. Esta declaração se articula em grande parte, pela crítica direta ou indireta ao que esses mesmos indivíduos percebem como elementos ou posturas presentes na onda anterior que dificultam o desenvolvimento da ficção científica nacional. A segunda característica, por sua vez, é o surgimento de um subgênero ou movimento que reflita as visões, demandas e perspectivas para essa literatura defendidas por representantes da nova onda. No caso da Segunda Onda, essa postura ganhou forma em duas expressões: "O Manifesto Antropofágico da Ficção Científica Brasileira” (1988), de Ivan Carlos Regina e o subgênero tupinipunk, criado por Roberto de Sousa Causo em 1989. 
Concebido no final da década de 1980 e tomando como inspiração "O Manifesto Antopófago" (1928), de Oswald de Andrade, o "Movimento Supernova", que eventualmente ficou conhecido como "O Manifesto Antropofágico da Ficção Científica Brasileira", foi marcado pela busca de uma posição crítica da ficção nacional em relação à produção de FC produzida no mundo anglófono no que se refere ao lugar marginal ocupado pelo Brasil enquanto país não produtor de ciência e tecnologia. (PEREIRA, 2005, p. 54). Essa reflexão, que estava ausente de maneira formal entre os escritores e escritoras da Primeira Onda durante a década de 1960, denunciava que,

A ficção científica brasileira não existe.

A cópia do modelo estrangeiro cria crianças de olhos arregalados, velhinhos tarados por livros, escritores sem leitores, homens neuróticos, literaturas escapistas, absurdos livros que se resumem as capas e pobreza mental, colônias intelectuais, que procuram, num grotesco imitar, recriar o modus vivendi dos países tecnologicamente desenvolvidos.

A ficção científica nacional não pode vir a reboque do resto do mundo. Ou atingimos sua qualidade ou desaparecemos. (REGINA, 1993, p. 9-10)

Ainda que, como assinala Elizabeth Ginway (GINWAY; CAUSO, 2010, p. 24), o Manifesto Antropofágico da Ficção Científica Brasileira não tenha fomentado um debate teórico mais aprofundado sobre os rumos da FC em nosso país, ele indubitavelmente levantou questões que ainda se fazem sentir entre quem escreve e lê essa literatura em nosso país.

O tupinipunk, por sua vez, surgiu no contexto da influência que o movimento cyberpunk exerceu sobre a ficção científica norte-americana e brasileira na década de 1980 e 1990 (MORANU, 2010, p. 9). Foi durante esse período que o escritor e pesquisador Roberto de Sousa Causo, ao observar como o cyberpunk estava sendo trabalhado de forma diferenciada em obras nacionais como Silicone XXI (1985), de Alfredo Sirkis e alguns contos de Braulio Tavares, resolveu criar um nome para este novo subgênero: “... durante o lançamento do primeiro livro de contos de Braulio Tavares, A Espinha Dorsal da Memória (1989), na Livraria Paisagem em São Paulo, eu cunhei o neologismo "tupinipunk"." (CAUSO, 2013, p. 224). Posteriormente, no artigo "Discovering and Rediscovering Brazilian Science Fiction: An Overview." (2010), escrito em coautoria com a pesquisadora norte-americana M. Elizabeth Ginway, Causo explicaria as diferenças entre o cyberpunk e o tupinipunk:

Diferente do cyberpunk norte-americano, as questões do tupinipunk repousam menos em uma fascinação com o ciberespaço e implantes do que em um ambiente urbano onde a tecnologia, a sensualidade, 0 misticismo, e um perspectiva política terceiro-mundista se misturam em um caleidoscópio de contos de fadas de aventuras urbanas em suas capitais modernas. (2010, p. 22).

Entre 1986 e 1995 obras nacionais surgiram alinhadas com a abordagem tupinipunk. Dentre outros exemplos, citamos contos e romances como "Jogo rápido" (1989), de Braulio Tavares; Santa Clara Poltergeist (1991) e Instinto Básico (1992), ambos de Fausto Fawcett; "O Caipira Caipora" (1993), de Ivan Carlos Regina e Piritas Siderais: Romance Cyberbarroco (1994), de Guilherme Kujawski. 
Ainda que seu surgimento esteja vinculado ao período da Segunda Onda da ficção científica brasileira, o tupinipunk avançou pelo século XXI e se encontra ativo em nosso meio literário. São exemplos deste subgênero neste novo milênio o conto "Visita Veneno" (2005) e o romance Favelost (The Book) (2012), ambos de Fausto Fawcett; a noveleta "Questão de Sobrevivência" (2005), de Carlos Orsi; o conto "Instinto Materno" (2010), de Pedro Vieira e a noveleta "A Lua É uma Flor sem Pétalas" (2012), de Cirilo S. Lemos.

A permanência da Segunda Onda em meio a manifestação da Terceira Onda, cujo início ocorreu em 2004 (CAUSO, 2013, p. 221) evidencia a terceira característica das ondas da FC: a ascensão de uma nova onda não implica no desaparecimento da anterior, mas sim na coexistência entre elas, promovendo um processo contínuo de movimentação na ficção científica brasileira. Esse dinamismo se formaliza na continuidade de publicações e ações neste início da terceira década do século XXI, mesmo entre quem desenvolve trabalhos em nada vinculados ao tupinipunk, levadas a cabo por escritores e escritoras identificados aqui como originários da Segunda Onda. A percepção deste fenômeno reforça a relevância do conceito das ondas como instrumento de análise da evolução da FC nacional. Dentro desta leitura, percebe-se que a mudança entre as ondas não ocorre por conta da idade dos escritores e das escritoras ou das temáticas e subgêneros abordados, mas sim do aparecimento de um zeitgeist que demanda novas formas de expressão da ficção científica em relação ao contexto literário anterior, algo visto na ascensão da Terceira Onda.

\section{Onde as ondas quebram: reflexões sobre a Terceira Onda}

A Terceira Onda da ficção científica se formou no lastro da chegada da Internet 2.0 e o gradual avanço da banda larga no Brasil, resultando na possibilidade de interação entre os usuários da rede mundial de computadores por meio de fóruns de debate, fóruns e podcasts. Esse sistema ampliou o papel desenvolvido na década anterior pelos fanzines, clubes de leitura e editoras, predominantemente organizado e controlado por homens, permitindo a democratização da cena literária. Destaque para os espaços conquistados, em blogues, revistas eletrônicas, editoras e podcasts, por mulheres e pessoas ligadas ao grupo LGBTQIA+ como, dentre outros nomes, Ana Cristina Rodrigues, Cristina Lasaitis, Lady Sybylla, Ursulla Mackenzie, Jana Bianchi, Anna Fagundes Martino, Roberta Spindler, Clara Mandrigano, Lu Evans, Carol Chiovatto, Caroline Façanha, Nikelen Witter, Ana Rüsche, Camila Fernandes, Claudia Dugim, Alexey Dodsworth, Thiago Ambrósio Lage e Alliah. As duas primeiras décadas do século XXI também foi o momento de estreia ou maior visibilidade de escritores como, por exemplo, Felipe Castilho, Romeu Martins, Tibor Moricz, Ricardo Labuto Gondim, Rodrigo Ortiz Vinholo, Ademir Pascale, Roberto Fiori, Eric Novello, Osíris Reis, Luiz Bras, Enéias Tavares, André Zanki Cordenonsi, André Cáceres, Michel Peres e Jean Gabriel Álamo.

Representada em grande parte por uma geração cuja comunicação e visão de mundo foram guiadas pela influência das redes sociais, as ações mais visíveis desta Terceira Onda refletiram o que Félix Guattari e Suely Rolnik identificaram como "desterritorialização": 
0 território pode se desterritorializar, isto é, abrir-se, engajar-se em linhas de fuga e até sair do seu curso e se destruir. A espécie humana está mergulhada num imenso movimento de desterritorialização, no sentido de que seus territórios "originais" se desfazem ininterruptamente com a divisão social do trabalho, com a ação dos deuses universais que ultrapassam os quadros da tribo e da etnia, com os sistemas maquínicos que a levam a atravessar cada vez mais rapidamente, as estratificações materiais e mentais (GUATTARI; ROLNIK, 1986, p. 323).

Em um primeiro momento, esta desterritorialização se fez notar pela execução de uma visão mais ampla do que seria a identidade da ficção científica nacional em um mundo globalizado. Percebe-se neste ponto o almejo do reconhecimento e maior inserção da ficção científica brasileira no plano externo. Este processo se exemplificou tanto na busca de escritores e escritoras por publicações e parcerias em revistas internacionais, principalmente do mundo anglófono, quanto na construção de diálogos mais próximos e constantes com a comunidade global da ficção científica por meio de eventos. 0 resultado desse quadro aponta para a imediata consequência da desterritorialização, que é a reterritorialização, ou seja, o movimento de construção de um novo território (DELEUZE; GUATTARI, 1997, p. 224). Assim, a partir da percepção de um país intrinsicamente conectado em uma aldeia global que compartilha muitos dos problemas e questões presentes em outros países, a ficção científica da Terceira Onda, em termos gerais, concebe um novo lugar para a FC do país ao considerar que ser global também é ser nacional.

Da mesma forma que no manifesto de Ivan Carlos Regina de 1988, e evidenciando a constituição de uma onda distinta em relação à ficção científica praticada desde a década de 1980 pela Segunda Onda, a Terceira Onda também apresentou um manifesto que capturou a postura de parte significativa de escritores e escritoras identificados com este período. Trata-se do "Manifesto AntiBrasilitite", redigido pelo escritor Osíris Reis e publicado de forma online em 2005:

Não é necessário citar o Brasil numa obra de ficção para que ela seja brasileira. Acreditamos que o autor e o realizador expressa sua brasilidade no estilo e nas idéias defendidas em sua obra, mesmo quando situa sua história de forma cosmopolita ou até fora do Brasil, sem necessidade de explicitar a brasilidade da mesma (REIS, 2019).

Percebemos aqui o alinhamento do manifesto com os conceitos de desterritorialização e reterritorialização de Félix Guattari, Gilles Deleuze e Suely Rolnik. Essa visão de Osíris Reis é melhor explicada em sua entrevista concedida ao também escritor Romeu Martins para o blog Overmundo: "Creio que nunca engoli muito bem o etnocentrismo, a idéia de que a cultura em que crescemos é melhor ou deva ser mais valorizada que as outras. Não curto o nacionalismo em si, na verdade esse sentimento até me irrita um pouco" (MARTINS, 2007). Por um lado, conforme já exposto, esse posicionamento apontou para uma abertura de possibilidades para a ficção científica do Brasil em termos de divulgação, circulação e maior valorização dessa literatura no próprio mercado literário nacional. Todavia, em outra leitura, os pontos defendidos pelo manifesto AntiBrasilitite deixavam claro que, antes de privilegiar a exploração das contradições e particularidades da cultura brasileira das grandes metrópoles do sudeste, como faz o tupinipunk, a

Memorare, Tubarão, v. 8, n. 1, jan./jun. 2021. ISSN: 2358-0593 
Terceira Onda se voltou para o global. São exceções neste quadro experiências como a coletânea Solarpunk (2013), publicada pela Editora Draco e projetos como o "Brasiliana SteamPunk", levado a cabo pelo escritor e pesquisador Enéias Tavares. Como Elizabeth Ginway e Roberto de Sousa Causo criticam em seu artigo de 2010:

A mais nova geração de escritores, ativos na internet, se enxerga como uma vanguarda literária. 0 "Manifesto AntiBrasilitite" de 2005 e sem autoria [...], por exemplo, é típico de uma geração que considera a Segunda Onda como muito nacionalista e ultrapassada, e deseja fortemente se tornar parte da fc global. Isto revela uma nova sede por internacionalização em tema e conteúdo, alimentada pela internet, filmes e televisão. [...] A Terceira Onda, ao mesmo tempo em que está familiarizada com escritoras e escritores brasileiros do passado, geralmente considera que elas e eles sejam de relevância limitada para as suas próprias produções. A nova geração enxerga o gênero como dela própria para criar, de uma forma sincrônica ao invés de diacrônica, talvez por causa do imediatismo da internet e do desejo de romper com o passado. (GINWAY; CAUSO, 2010, p. 24-25).

Temos, portanto, a manifestação da quarta característica desse termo que cobre as periodizações da ficção científica brasileira: a falta de diálogo maior entre representantes das diferentes ondas. Ainda que, conforme explicado na terceira característica das ondas, elas permanecem em coexistência ativa ao longo das décadas, elas não se tocam o suficiente a ponto de promoverem uma troca ativa de experiências que enriquecia todo o sistema dessa literatura no Brasil.

Como no caso do subgênero tupinipunk para a Segunda Onda, a Terceira Onda também possui no fantasismo o seu movimento literário característico. Apresentado no capítulo final do estudo históricoliterário Fantástico brasileiro: 0 insólito literário do Romantismo ao Fantasismo (2018), de Bruno Anselmi Matangrano e Enéias Tavares, o fantasismo abarca as configurações da fantasia, do horror e da ficção científica brasileira no século XXI e o maior espaço conquistado por estas três vertentes da Literatura Fantástica no mercado e na academia brasileira:

O fantasismo se encontra difundido [...] ao longo das duas primeiras décadas do século XXI [...] é um novo movimento literário cuja origem parece coincidir com o novo século, mas, sobretudo, a partir de 2010, quando o mercado de literatura fantástica brasileira começa a se estruturar de fato. (MATANGRANO; TAVARES, 2018, p. 262)

Segundo seus idealizadores, o fantasismo se faz sentir por meio de quatro fatores: a) a publicação de títulos que alcançaram notoriedade, b) a progressiva criação de editoras e de selos específicos voltados às vertentes do insólito ficcional, c) o incrível aumento de estudos teóricos e a crescente penetração dessas questões nos meios universitários e acadêmicos brasileiros, bem como d) a criação de eventos, prêmios e reuniões congregando fãs, escritores, editores e críticos em torno de um objetivo comum: debater e valorizar a produção fantástica nacional. (MATANGRANO; TAVARES, 2018, p. 264-265). Nessa conjuntura de defesa, produção e divulgação da literatura fantástica, o fantasismo encontra expressão por meio da ênfase na criação de universos ficcionais, no pendor para a intertextualidade e na busca de 
abrasileiramento, aclimatação e promoção da cor local de modos narrativos estrangeiros tradicionais da literatura fantástica.

Observa-se no fantasismo a presença mais uma vez da reterritorialização marcante da Terceira Onda, resultando em produções literárias brasileiras alinhadas com o cenário internacional atual do fantástico. Todavia, ainda que defenda "a continuidade a toda uma tradição, brasileiríssima em essência, que remonta o romantismo e toda a nossa história subsequente" (MATANGRANO; TAVARES, 2018, p. 269) o fantasismo não deixa claro exatamente qual seria a constituição e amplitude dessa tradição essencialmente brasileira.

Em um país de geografia e desigualdades continentais, forjado por uma histórica marginalização de regiões e grupos minoritários em relação aos centros de poder (majoritariamente controlados por brancos) localizados na Região Sudeste e Sul do Brasil (SILVA, 2008, p. 132) a pergunta que surge é: De qual Brasil estamos tratando? A reflexão sobre essa questão ganha mais relevância quando, como já descrito aqui, lembramos que a Terceira Onda, em termos gerais, enxerga a brasilidade inserida em um contexto global e não local. Esse cosmopolitismo identitário, por sua vez, encontra acolhimento no excludente mercado literário de Rio de Janeiro e São Paulo.

Assim sendo, ao estabelecer, por exemplo, "a publicação de títulos que alcançaram notoriedade" e "a criação de eventos, prêmios e reuniões congregando fãs, escritores, editores e críticos", como marcas de fortalecimento da literatura fantástica brasileira atual, o fantasismo desconsidera a histórica marginalidade da produção de escritoras e escritores negros e de regiões como o Norte, o Nordeste e o CentroOeste, alijados tanto do processo de publicações por editoras tradicionais no Sul e Sudeste quanto da presença em eventos literários nestas mesmas regiões. Em meados de segunda década do século XXI esta situação encontrou seu ponto de saturação quando essas vozes marginalizadas começaram a usar os mesmos recursos digitais que ajudaram a disseminar a Terceira Onda para denunciar sua situação e conquistar seus espaços de expressão, dando margem para o que acreditamos seja a manifestação da Quarta Onda da ficção científica brasileira.

\section{Onda diferente: estamos surfando a Quarta Onda da ficção científica brasileira?}

Após esse percurso necessário pelas três primeiras ondas da ficção científica brasileira, visando o melhor entendimento por trás do conceito de periodização dessa expressão da literatura fantástica em nosso país, chegamos ao próximo ponto deste estudo: Estaríamos vivenciando neste início da terceira década do século XXI os efeitos da Quarta Onda da FC brasileira? Para responder a essa questão comecemos relembrando quais são as quatro características identificadoras de uma onda da FC brasileira levantadas ao longo deste estudo:

a) a existência de um manifesto ou posicionamento formal de pessoas identificadas com o momento literário da ficção científica em que elas estão inseridas; 
b) o surgimento de um subgênero ou movimento que reflita as visões, demandas e perspectivas para essa literatura defendidas por representantes da onda em questão;

c) a coexistência da nova onda com as manifestações que a precederam;

d) a falta de diálogo sistemático entre representantes das diferentes ondas visando troca de experiências ou realização de projetos em comum.

Uma das primeiras menções à Quarta Onda ocorreu em 02 setembro de 2019 no artigo "Amazofuturismo e Cyberagreste: por uma nova ficção científica brasileira”, de Lidia Zuin, para o portal de notícias UOL TAB. Na matéria, a jornalista e pesquisadora chama a atenção para o surgimento de novas configurações da ficção científica no Brasil na segunda década do século XXI:

Hoje, já na quarta onda da ficção científica brasileira, vemos autores que exploram subgêneros populares atualmente, como o afrofuturismo, no qual se destaca a obra "0 Caçador Cibernético da Rua 13", de Fábio Kabral, ou o romance steamfunk de "O Baronato de Shoah", de José Roberto Vieira, ou a versão LGBT, a partir de movimentos como o Manifesto Irradiativo. E acontece nestes dias a ascensão de uma nova frente especulativa: o cyberagreste.

Em resposta imediata à publicação da matéria sobre o aparecimento de uma nova visão do Nordeste brasileiro a ser trabalhada pela ficção científica nacional, alguns artistas desta região reagiram ao que foi considerada a reiteração de um olhar viciado em relação ao Nordeste perpetrado pelas regiões sul e sudeste do país. Acreditamos que essa contestação, que como veremos adiante, neste caso específico, assumiu a forma do sertãopunk, refletiu o aprofundamento e ampliação das mudanças em curso na ficção científica brasileira desde a Terceira Onda sobre a visibilidade conquistada por discursos antes eclipsados pelos sistemas detentores de poder no meio editorial e nos veículos de comunicação.

Essas mudanças da FC nacional, também mencionadas por Lidia Zuin em seu artigo, já haviam começado a se manifestar em meados da segunda década do século XXI, por conta da publicação online do "Manifesto Irradiativo" em 2015. Temos assim, dentro da proposta defendida por esta pesquisa, tanto um marco inicial da Quarta Onda da ficção científica quanto um dos elementos identificadores da presença de uma Onda.

Concebido pelos escritores Jim Anotsu e Alliah, o Manifesto Irradiativo "é para todo mundo que já desejou ser aceito, para que saibam que sua representatividade importa" (ANOTSU; VIEIRA, 2015), conforme assinala a carta que acompanha o documento. Essa declaração ganhou sua primeira expressão no Encontro Irradiativo, ocorrido nos dias 7 e 8 de novembro na Biblioteca Viriato Corrêa, em São Paulo. Organizado em mesas de discussões, exposições e desfiles, o evento se pautou pelas referências que nortearam a tessitura do manifesto:

invocamos referências não-apologéticas dos quadrinhos americanos e japoneses, cinema de arte ou blockbuster, da música emocore ao rap queer, do Movimento Antropofágico, do Manguebeat, da cultura pop 
televisiva, da deepweb até a cultura de internet da superfície e todas as camadas intersticiais, do afrofuturismo de Janelle Monae, da artesabotagem e do terrorismo poético de Hakim Bey, do Manifesto Riot Grrrls, da desobediência civil, do DIY, do caos de nossas rotinas até o vórtice incomensurável do cosmos; (ANOTSU; VIEIRA, 2015)

A existência do manifesto enquanto estratégia de denúncia do lugar de exclusão de diversos grupos na sociedade brasileira apontou para o fato de que, ainda que o advento da Terceira Onda em 2004 tenha iniciado um processo lento de abertura e democratização da cena da literatura fantástica nacional, principalmente em relação às mulheres, a permanência aguda desse sistema literário marginalizante uma década depois passou a demandar iniciativas mais diretas também de outros grupos além dos já abarcados pela documento de Jim Anotsu e Alliah. Assim como ocorrido anteriormente em outras ondas com o tupinipunk e o fantasismo, as demandas colocadas por esta nova conjuntura semearam entre 2014 e 2015 o terreno para a chegada ao Brasil e eclosão em nossas terras de subgêneros literários intrinsicamente conectadas com os pontos postulados pelo Manifesto Irradiativo. Atestando a segunda característica de uma onda da ficção científica, focaremos aqui brevemente em três dessas expressões: afrofuturismo, amazofuturismo e sertãopunk.

\subsection{Afrofuturismo}

Cunhado em 1994 pelo crítico Mark Dery no ensaio "Black to the future", o termo "Afrofuturismo" surgiu como resultado de uma série de entrevistas com nomes da ficção científica afro-americana como Samuel R. Delany, Greg Tate e Tricia Rose. No texto de apresentação dessas conversas, Dery refletiu sobre a pouca presença de escritoras e escritores negros na ficção científica norte-americana uma vez que, como também lembra o crítico Adam Roberts (2000, p. 28), essa expressão da literatura fantástica tem no encontro com a diferença um dos componentes veiculadores dos novuns da FC. Assim sendo, questões como preconceito e exclusão, que sempre fizeram parte do dia a dia das pessoas negras, poderiam ser exploradas via ficção científica por artistas desse grupo. Todavia, como recorda Octavia E. Butler sobre uma conversa que teve com sua tia nos anos 60 , durante sua adolescência, a realidade era outra:

"Quero ser uma escritora quando crescer", eu disse /.../ "Querida... Negros não podem ser escritores." "Por que não?" "Eles simplesmente não podem". Eu era mais irredutível quando não sabia sobre o que eu estava falando. Nos meus treze anos de vida, eu nunca havia lido uma palavra impressa que eu soubesse ter sido escrita por uma pessoa negra. Minha tia era uma mulher adulta. Ela sabia mais do que eu. E se ela estivesse certa? (BUTLER, 1996, p. 127, tradução do autor).

Pensando em nomes como Octavia E. Butler, Steve Barnes e Charles Saunders, dentre outros, Mark Dery chamou de afrofuturismo a produção desses escritores e escritoras, explicando-a como "ficção especulativa que trata temas afro-americanos e aborda as preocupações de afro-americanos no contexto da tecnocultura do século XX" (DERY, 1994, p. 180, tradução do autor). Destaca-se que apesar de partir da literatura, o crítico criou o termo já contemplando outras manifestações 
artísticas como a música, o cinema e as artes plásticas. Inicialmente centrada no contexto dos Estados Unidos da América, o conceito foi sendo ampliado, adquirindo dimensão global.

Segundo o pesquisador Waldson Gomes de Souza (2019, p. 93), as discussões sobre o afrofuturismo no Brasil tem os seus momentos iniciais no ano de 2014, mesmo ano em que é publicada a obra Ritos de passagem (2014), de Fábio Kabral, sendo seguida, no campo da ficção científica, por 0 caçador cibernético da rua 13 (2017), do mesmo autor. Outras publicações que exemplificavam a disseminação do afrofuturismo no Brasil em meados da segunda década do século XXI são Cidade de Deus Z (2015), de Julio Pecly; Brasil 2408 (2016-2017), Sankofia: breves histórias afrofuturistas (2018), ambos de Lu Ain-Zaila e "Despedida de Outono: um drama steamfunk" (2018), de Oghan N'Thanda. Ao apontar as especificidades do afrofuturismo brasileiro levantadas por ele nos trabalhos de Fábio Kabral, Julio Pecly e Lu AinZaila em contraste com a forma afro-americana, Souza (2019, p. 93) observa que:

Apesar de possuírem propostas e focos diferentes, alguns temas como desigualdade social, morte, sonho, memória e desejo por mudança são comuns aos romances. Conectam-se questões e problemas relevantes na sociedade brasileira, nos fornecendo uma boa noção de como o afrofuturismo pode ser explorado na nossa literatura.

São sintomáticos também da disseminação do afrofuturismo no Brasil, a disponibilidade em língua portuguesa, após décadas de atraso, da obra da escritora afro-americana Octavia E. Butler, figura central do Afrofuturismo, e também o surgimento de editoras independentes focadas em escritores e escritoras negros nacionais, como, dentre outras, a Editora Malê e a Kitembo Edições Literárias, surgidas respectivamente em 2015 e 2019.

Cabe destacar, todavia, que se por um lado o afrofuturismo se colocou como um renovador da ficção científica brasileira ao se constituir um meio para a voz negra na literatura fantástica nacional, por outro ele ainda reflete a histórica concentração de escritores, escritoras e casas editoriais na Região Sudeste. A Editora Malê, por exemplo, se localiza no Rio de Janeiro, ao passo que a Kitembo Edições Literárias tem sua base em São Paulo. Sobre os nomes citados aqui, que vem impulsionando o afrofuturismo brasileiro, todos publicam na Região Sudeste. Em alusão a este fato, Waldson Gomes de Souza (2019, p. 88) comenta sobre Fábio Kabral, Julio Pecly e Lu Ain-Zaila que, "Os três autores nasceram no Rio de Janeiro, então o recorte não mostra a perspectiva de autores de outros estados, o que contribuiria para pensar de fato em Brasil e não apenas na região sudeste." Foi justamente essa urgência de se ouvir vozes da ficção científica nacional oriundas de outras regiões do Brasil, distantes do eixo Sul e Sudeste, que fez surgir dois movimentos literários intimamente pautados pela diversidade cultural de nosso país: o amazofuturismo e o sertãopunk. Comecemos pelo primeiro.

\subsection{Amazofuturismo}

Ao longo de sua história, a Amazônia sempre foi vista por olhos estrangeiros como um mundo à parte, um laboratório natural para o 
exercício da imaginação de viajantes, exploradores e pesquisadores, como o geógrafo alemão Alexander non Humboldt, que em 1799 tentou percorrer toda a extensão do Rio Amazonas, mas foi impedido pelo governo lusitano. Assim ocorreu anteriormente também com Pedro de Rates Henequim, que viveu no Brasil entre 1702 e 1722 e acreditava que aqui havia sido a morada de Adão, além de local onde se encontrava a Árvore da Vida. Tanta certeza ele tinha de ter habitado o "Paraíso Terreal" - sendo o Amazonas o maior rio do Éden - que, ao voltar à Portugal, foi processado e executado em 1744 por ordem do Tribunal do Santo Ofício pelo crime de heresia e apostasia (VALENTIM, 2020). Já no século XX, nos primeiros momentos da ficção científica brasileira, o romance Amazônia misteriosa (1925), do escritor carioca Gastão Cruls também apresentou a região pelo víeis do olhar europeu diante de uma terra exótica (SILVA, 2008). Todavia, após quase um século depois de Cruls, surge na Região Norte uma perspectiva de abordagem da ficção científica criada por artistas pertencentes a este local.

Assim como o cyberagreste, o amazofuturismo tem sua gênese na ilustração. Porém, diferente do primeiro, que ainda permanece muito circunscrito ao seu campo de origem, o amazofuturismo vem gradativamente capturando a imaginação de escritores e escritoras vinculados à Região Norte do Brasil. 0 resultado desse movimento é o enriquecimento das possibilidades narrativas da ficção científica em nosso país a partir da abordagem da diversidade cultural que o compõe.

Criado pelo rondoniense João Queiroz, este subgênero da ficção científica surgiu inicialmente como um experimento estético de título "Cyberamazon" publicado em 08 de maio de 2019 no perfil do artista na rede social Instagram. Como o ilustrador explica em entrevista à Lidia Zuin para o portal TAB UOL:

"O amazofuturismo surgiu de uma convergência de inspirações e necessidades. Alguns meses antes de criar a ilustração Cyberamazon, eu estava interessado no cyberpunk e toda sua teoria e estética. Fiz alguns trabalhos com esse tema e logo percebi que a estética atual do gênero estagnou em um retrofuturismo dos anos 80 , porque, claro, Blade Runner, Akira, Alita e Ghost in the Shell continuam sendo grandes fontes de inspiração"... (2019)

Em busca de novas direções criativas, João Queiroz se voltou para um subgênero derivado do cyberpunk com destaque no cenário da ficção científica brasileira: o solarpunk:

No meio das minhas pesquisas encontrei o solarpunk e isso me inspirou também. Também foi uma forma de afirmação étnica, já que eu nunca tinha visto o povo caboclo e indígena do Norte serem inseridos na ficção científica. A partir disso, comecei a brincar com os conceitos de alta tecnologia, povos originários e integração com a natureza e o amazofuturismo foi se formando (ENTREVISTA, 2020).

Chama a atenção no amazofuturismo, em um primeiro momento, a ausência de um grupo organizado que possa promover debates para a disseminação desse subgênero visando o seu consequente estabelecimento como expressão da ficção científica brasileira. Entretanto, esta mesma falta de organização maior não vem se constituindo um obstáculo, visto que ele vem crescendo de forma orgânica ao atrair artistas, ligados à cultura da Região Norte, que tem

Memorare, Tubarão, v. 8, n. 1, jan./jun. 2021. ISSN: 2358-0593 
encontrado no amazofuturismo território fecundo para tratar questões identitárias próprias ou temas pertencentes aos povos originais do Brasil e demais populações amazônicas. Como João Queiroz reconhece neste ponto: "O amazofuturismo ainda é terra incógnita, então quem sabe como ele irá evoluir a partir da contribuição de vários artistas com perspectivas diferentes? Acho que a única coisa que deve se manter em mente é o respeito e a valorização das culturas dos povos originários." (ENTREVISTA, 2020).

A primeira experimentação literária do amazofuturismo, antes mesmo da criação do termo, pode ser encontrada no conto "O Pajemancer", de Mario Bentes, publicado na coletânea 2084: Mundos Cyberpunks (2018), da editora Lendari. Nesta ficção curta, Bentes fez uso de sua experiência como morador de Manaus para revisitar alguns dos pontos históricos e turísticos da capital amazonense para pensar um futuro tecnológico e noir adaptados ao contexto brasileiro (ZUIN, 2019).

Em termos de narrativas longas, a ênfase de João Queiroz no cuidado a ser observado na abordagem da cultura nativa norteia a proposta do primeiro romance amazofuturista - Amazofuturismo (2021), de Rogério Pietro. Na obra, ambientada no período do descobrimento do Brasil, Pietro apresenta o choque entre a fictícia aldeia dos Tabora Boti, possuidora de tecnologia altamente desenvolvida e em harmonia com a natureza, e colonizadores europeus detentores de maquinário steampunk. Sobre os cuidados na representação da cultura nativa em sua obra, o escritor salienta:

Um dos aspectos fundamentais do amazofuturismo é que a tecnologia deve ser inovadora e única. Ela deve conversar com os elementos culturais da região, e não importar tecnologias que existem em outros povos da atualidade. A finalidade não é transformar o índio em uma coisa que ele não é, e sim imaginar como serão as tecnologias futuras com base no que os índios possuem culturalmente. 0 respeito à natureza é um desses aspectos. (AMAZOFUTURISMO, 2021)

Refletindo em seu nome a mesma busca de amplitude artística do afrofuturismo, o amazofuturismo entra na terceira década do século XXI ampliando os seus campos de expressão para o universo da música e outras formas artísticas. Segundo o ilustrador e compositor Lucas Castanha (2020, p. 14) ao falar dessas perspectivas: "o conceito amazônida-futurista ainda passa no momento, por uma fortificação entre seus próprios adeptos nas diversas áreas de arte e cultura inseridas nele, para que a partir de então seja construída a história de sua propagação em maior escala em sua região de origem e assim sucessivamente." Neste sentido, espera-se que editoras localizadas no norte do Brasil ou que nela surgiram e que publicam literatura fantástica brasileira, como a Para.grafo, a Lendari e a Cyberus, possam se interessar em acolher o amazofuturismo.

Uma vez abordada brevemente as configurações do amazofuturismo enquanto indicador na Região Norte do surgimento da Quarta Onda da ficção científica brasileira, vejamos como estereótipos recorrentes sobre o nordeste brasileiro fizeram surgir o sertãopunk. 


\subsection{Sertãopunk}

Partindo da utilização do termo "punk" no sentido de atitude contestadora ao poder vigente (FERNANDES, 2006, p. 49) em conjunto ao espaço geográfico-cultural do sertão, o sertãopunk ganhou visibilidade em 04 de setembro de 2019 no artigo "Estão inventando o Nordeste. De novo.", do escritor baiano Alan de Sá, publicado na plataforma de blog Medium. Este texto foi seguido pelos artigos "Não troco o meu "oxente" pelo "cyberagreste" de ninguém!" e "Sudestino criando é artista, mas nordestino criando pode não?", de 05 e 06 de setembro de 2019, do escritor baiano Alec Silva, publicado em seu blog pessoal. Dando continuidade ao seu primeiro texto, Alan de Sá desenvolveu o conceito do sertãopunk no artigo "Por que fazer o Nordeste sertãopunk?”, de 06 de setembro de 2019, novamente veiculado no Medium. Destaque ainda neste primeiro momento de textos fundadores os artigos "O regionalismo terá sido reduzido a uma estética de exotismo?", de 05 de setembro de 2019, do escritor mineiro José Geraldo Gouvêa e "Quem podem imaginar o Nordeste?", de 15 de setembro de 2019, do escritor baiano Ricardo Santos.

0 que todos estes textos apresentam em comum é a reação crítica ao já citado artigo "Amazofuturismo e Cyberagreste: por uma nova ficção científica brasileira”, de Lidia Zuin de 02 de setembro de 2019 e, mais especificamente dentro do artigo, ao cyberagreste criado pelo ilustrador gaúcho Vitor Wiedergrün. Ao reiterar imagens consagradas pelo discurso do sul e sudeste na TV, cinema, literatura e veículos de comunicação e marketing em relação ao imaginário do nordeste, o cyberagreste perpetuou estereótipos da região como uma terra de cangaceiros, beatos, seca e atraso.

O sertãopunk objetiva dar um basta a esta visão a partir da proposição de uma nova abordagem que reflita tanto a realidade do Nordeste no século XXI quanto a pluraridade cultural da região. Como explica Alan de Sá: "O termo sertãopunk nasce da junção de duas palavras: do sertão, que é maior subregião do Nordeste, englobando oito dos nove estados. 0 punk vem da palavra contravenção, de criticar a ordem estabelecida." (GARCIA, 2019).

Diferente do amazofuturismo, o sertãopunk tem nos seus criadores - os escritores baianos Alan de Sá e Alec Silva e a escritora cearense Gabriele Diniz - um grupo organizado que vem articulando o desenvolvimento e disseminação deste novo movimento literário por meio de artigos, vídeos, eventos e obras publicadas: "Nunca foi uma ideia de, somente, resposta visual. Mas, de fato, estruturar um gênero literário do zero, pensar no desenvolvimento das narrativas e de como gostaríamos de ver nossa região representada na ficção especulativa." (SÁ, 2019).

Tomando como referências o realismo mágico (trazido por Alec Silva), o solarpunk (contribuição de Gabriele Diniz) e o afrofuturismo (agregado por Alan de Sá) (GARCIA, 2019), o sertãopunk se caracteriza pela utilização de elementos de subversão às imagens enviesadas do Nordeste, sendo eles: 
- Um Nordeste onde os avanços tecnológicos, sobretudo ecológicos, proporcionaram alta qualidade de vida para os nordestinos;

- Presença de desordem social por parte de uma elite coronelista emergente e financiada por poderosos grupos de outras regiões;

- Reformulação do processo migratório brasileiro;

- Nordeste como polo independente de desenvolvimento intelectual e cultural;

- Uso da oralidade, de elementos culturais e das diversas lendas e religiões da região na narrativa (SÁ, 2019).

Publicadas de forma independente ou por editoras como a nordestina Corvus, as obras sertãopunk tem no conto "O sertão não virou mar" (2020), de Gabriele Diniz o seu marco inicial. Outros exemplos do movimento são "Morte matada" (2020), de Gabriele Diniz; "A noite tem mil olhos" (2020), de Alec Silva; "Abrakadabra" (2021), de Alan de Sá e a coletânea Sertãopunk: histórias de um Nordeste do Amanhã (2020), de Alan de Sá, Alec Silva e Gabriele Diniz, obra que reúne contos e artigos sobre o movimento. Como ponto em comum entre as narrativas, percebe-se a abordagem do elemento insólito presente na cultura nordestina, algo presente na reflexão de Alec Silva sobre a sua visão de Nordeste:

O Nordeste que eu quero ver representado é o de cada escritor, do cordelista que reconta causos e revive o passado ao romancista que narra a aventura de um grupo de jovens perdidos nas grutas da Chapada Diamantina. Eu quero sentir o mesmo medo que eu sentia ao contemplar a escuridão na fazenda de meus avós. Quero reviver as lembranças da água salobra de Utinga (BA) lendo um conto sobre uma criança que acha um calango mágico. Não quero estereótipos, eu quero minha região, pedaço por pedaço, escrita por quem a entende e a respeita (algo que a antologia Estranha Bahia teve bastante êxito, ainda em 2015). Quero conhecer nossas lendas, quero conhecer nosso povo (assim como adoraria conhecer de qualquer região desse imenso Brasil)! (2019).

A citação acima reitera a proposta deste estudo de considerar o sertãopunk como movimento característico da Quarta Onda da ficção científica brasileira. De fato, percebemos no sertãopunk, no afrofuturismo brasileiro e no amazofuturismo o resgate do interesse nas identidades brasileiras. Se a Terceira Onda, conforme mencionado anteriormente, almeja a integração da identidade brasileira a um contexto global, levando a interpretação de uma diluição do que é ser brasileiro, na Quarta Onda temos a ênfase nas brasilidades como ponto de enriquecimento e distinção da literatura fantástica nacional em comparação com outras manifestações do insólito no mundo.

Esta postura da cultura local ajuda a entender o espaço que o sertãopunk vem ocupando em eventos internacionais, como a palestra "Alternative Futures: Brazilian Sertãopunk", proferida pelos criadores do movimento na Rutgers University em 23 de abril de 2021 e o painel "What Happens When Social Media and Self-Publishing Platforms Replace Traditional Models of Knowledge Production?", a ser realizado dentro do evento Digital Americas: 48th Conference of the Austrian Association for American Studies nos dias 30 e 31 de outubro de 2021. Esta visibilidade é parte do projeto dos idealizadores do sertãopunk 
para angariar mais escritores e escritoras para o movimento, assim como também para buscar ampliar sua presença em novas mídias e formas artísticas.

\section{Considerações finais}

Primeira Onda, Segunda Onda, Terceira Onda...Quarta Onda. Como foi mostrado ao longo deste artigo, a utilização do termo "Ondas da ficção científica brasileira" não tem apenas o propósito de propor balizas históricas para o entendimento da evolução da FC nacional. 0 levantamento aqui de suas características e a forma como elas vem se manifestando atestam a sua validade como ferramenta de compreensão não apenas da riqueza e diversidade da ficção científica em nossas terras, mas também dos desafios ainda impostos a esta vertente da literatura fantástica para a sua maior penetração na literatura brasileira.

Qual é o lugar da ciência na ficção científica de um país como o Brasil? De que "ciência" estamos falando? Como esta expressão da literatura fantástica se relaciona com diversas questões históricas da sociedade brasileira? Qual é a forma de diálogo estabelecido entre a FC nacional e a tradição norte-americana e europeia? Essas e outras questões estão por trás do surgimento das diferentes ondas, culminando na recente Quarta Onda.

Contemplando grupos e regiões antes desprovidas de representatividade, o afrofuturismo, o amazofuturismo e o sertãopunk são apenas algumas das formas atuais mais visíveis que demostram o amadurecimento da ficção científica do Brasil nesta terceira década do século XXI. Mais do que nunca, podemos dizer que a FC nacional reconhece hoje na multiplicidade cultural do seu passado e presente as ferramentas de construção de seu futuro.

\section{Referências}

AMAZOFUTURISMO: subgênero da ficção científica ganha seu primeiro romance por Rogério Pietro. Café com NERD. 02 fev. 2021. Disponível em https://cafecomnerd.com.br/amazofuturismo-subgenero-da-ficcao-cientificaganha-seu-primeiro-romance-por-rogerio-pietro Acesso em 23 abril 2021.

ANOTSU, J.; VIEIRA, V. (ALLIAH). Carta: Deflagrando Nossa Explosão de Diversidade. 12 jan. 2015. Disponível em: https://manifestoirradiativo.wordpress.com Acesso em 22 abril 2021.

ANOTSU, J.; VIEIRA, V. (ALLIAH). Manifesto irradiativo. 12 de Jan. de 2015. Disponível em: https://manifestoirradiativo.wordpress.com Acesso em 22 abril de 2021.

BELL, A. L.; YOLANDA M. G. Introduction. In: BELL, A. L.; YOLANDA M. G. (Eds.). Cosmos Latinos: An Anthology of Science Fiction from Latin America and Spain. Middletown, CT: Wesleyan UP, 2003. 1-19.

BUTLER, O. E.. Positive Obsession. In: BUTLER, Octavia E.. Bloodchild and other stories. London: Seven Stories Press, 1996, p. 123-136.

CASTANHA, L. Amazofuturistas em andamento. Tricerata, Belém, n. 02, p. 14-15, dez. 2020. Disponível em: https://editoracyberus.weebly.com/revistatricerata.html Acesso em 23 de abril de 2021. 
CAUSO, R. de S. Ficção científica, fantasia e horror no Brasil: 1875-1950. Belo Horizonte: Editora UFMG, 2003.

CAUSO, R. de S.. Ondas nas Praias de um Mundo Sombrio: New Wave e Cyberpunk no Brasil. Tese (Doutorado em Letras). Universidade de São Paulo, USP, 2013. Disponível em https://www.teses.usp.br/teses/disponiveis/8/8147/tde12032014-123051/pt-br.php Acesso em 27 de abril de 2021.

CUNHA, F.. A ficção científica no Brasil: um planeta quase desabitado. In: ALLEN, L. David. No mundo da ficção científica. São Paulo: Summus Editorial, 1974, p. 5-20.

DELEUZE, G.; GUATTARI, F.. Mil Platôs: capitalismo e esquizofrenia. Vol. 5. Trad. Peter Pál Pelbart e Janice Caiafa. Rio de Janeiro: Ed. 34, 1997.

DERY, Mark. Black to the Future: interviews with Samuel R. Delany, Greg Tate, and Tricia Rose. In: DERY, Mark (ed.). Flame Wars: The Discourse of Cyberculture. Durham, NC: Duke University Press, 1994, p. 179-222.

DUNBAR, D. L. Unique Motifs in Brazilian Science Fiction. Dissertação (Doctor of Philosophy with a Major in Spanish) Universidade do Arizona, Arizona, 1976. Disponível em: https://repository.arizona.edu/handle/10150/ Acesso em 22 de abril de 2021.

ENTREVISTA com o ilustrador João Queiroz. Tricerata, Belém, n. 02, p. 7-9, dez. 2020. Disponível em: https://editoracyberus.weebly.com/revista-tricerata.html Acesso em 23 de abril de 2021.

FERNANDES, F. A construção do imaginário cyber: William Gibson, criador da cibercultura. São Paulo: Editora Anhembi Morumbi, 2006.

GARCIA, C. Sertãopunk: as culturas do Nordeste como força motriz para a ficção científica brasileira. Portal Aprendiz. 11 out. 2019. Disponível em https://portal.aprendiz.uol.com.br/2019/10/11/sertaopunk-culturasnordeste-como-forca-motriz-para-uma-ficcao-cientifica Acesso em 23 abril 2021.

GINWAY, M. E.; CAUSO, R. de S. Discovering and Re-discovering Brazilian Science Fiction: An overview. Extrapolation, In: LIVERPOOL University Press Online, vol. 51, n 1, 2010, p. 13-39.

GUATTARI, F.; ROLNIK, S. Micropolítica: cartografias do desejo. Petrópolis: Vozes, 1996.

LEMOS, A. Ciberespaço e tecnologias móveis: processos de territorialização e desterritorialização na Cibercultura. In: 15o ENCONTRO Anual da Compós. Bauru, 2006. Disponível em https://www.facom.ufba.br/ciberpesquisa/andrelemos/territorio.pdf Acesso em 01 de maio de 2021.

MARTINS, R.. Entrevista: Osíris Reis. In: OVERMUNDO. 17 de out. 2007. Disponível em http://www.overmundo.com.br/overblog/entrevista-osiris-reis Acesso em 30 de abril de 2021.

MATANGRANO, B. A.; TAVARES, E.. Fantástico brasileiro: 0 insólito literário do Romantismo ao Fantasismo. Curitiba, PR: Arte \& Letras, 2018. 
MORANU, J. Introdução: Cyberpunk, Tupinipunk e Pós-Cyberpunk. In: DUPLO CYBERPUNK: 0 consertador de bicicleta, de Bruce Sterling [Trad. Carlos Angelo]; Vale-Tudo, de Roberto de Sousa Causo. São Paulo, Devir, 2010. p. 517.

PEREIRA, F. Fantástica Margem: o Cânone e a Ficção Científica Brasileira. Dissertação (Mestrado em Letras). Pontifícia Universidade Católica do Rio de Janeiro, Rio de Janeiro, 2005. Disponível em https://www.maxwell.vrac.pucrio.br/colecao.php?strSecao=resultado\&nrSeq=6493@1 Acesso em 23 de abril de 2021.

REGINA, I. C.. Manifesto Antropofágico de Ficção Científica. In: 0 fruto maduro da civilização. São Paulo: GRD, 1993. p. 9-10.

REIS, O. Manifesto AntiBrasilitite. In: MARTÍN, M. Manifesto AntiBrasilitite. 21 de maio 2019. Disponível em https://mapc.medium.com/manifesto-antibrazilititef7ff0aa9d14d Acesso em 01 de maio de 2021.

ROBERTS, A. Science Fiction. New York: Routledge, 2000. (The New Critical Idiom).

SÁ, A. Estão inventando o Nordeste. De novo. MEDIUM. 04 de set. 2019. Disponível em https://medium.com/alan-de-s\%C3\%A1/est\%C3\%A3o-inventando-onordeste-de-novo-808943b6a759 Acesso em 22 de abril de 2021.

SÁ, A. Por que fazer o Nordeste sertãopunk? MEDIUM. 06 de set. 2019. Disponível em https://medium.com/alan-de-s\%C3\%A1/sertaopunk-c0e0015a13ea Acesso em 30 de abril de 2021.

SILVA, A. Não troco o meu “oxente” pelo “cyberagreste” de ninguém!. 05 de set. 2019. Disponível em http://alecsilva-escritor.blogspot.com/2019/09/nao-troco-omeu-oxente-pelo.html Acesso em 30 de abril de 2021.

SILVA, A. Sudestino criando é artista, mas nordestino criando pode não? Disponível em https://alecsilva-escritor.blogspot.com/2019/09/sudestino-criando-eartista-mas.html? Acesso em 30 de abril de 2021.

SILVA, A. M. O admirável mundo novo da República Velha: 0 nascimento da ficção científica brasileira no começo do século XX. Tese (Doutorado em Literatura Comparada). Universidade Federal do Rio de Janeiro, Rio de Janeiro, 2008.

SOUSA, R. T. Arqueologia da protoficção científica brasileira e a contribuição da literatura maranhense. Dissertação (Mestrado em Letras). Universidade Federal do Maranhão. São Luís, 2021.

SOUZA, W. G. Afrofuturismo: o futuro ancestral na literatura brasileira contemporânea. Dissertação (Mestrado em Literatura). Universidade de Brasília. Brasília, 2019.

VALENTIM, I. A. R. Nas malhas da Inquisição: as proposições heréticas do milenarista Pedro de Rates Henequim frente ao Tribunal do Santo Ofício Português (16801744). Contraponto. n. 1. v. 9. 2020, p. 176-198. Disponível em https://revistas.ufpi.br/index.php/contraponto/article/view/11480 Acesso em 08 de maio de 2021.

ZUIN, L. Amazofuturismo e Cyberagreste: por uma nova ficção científica brasileira. In: TAB UOL. 02 de set. 2019. Disponível em https://lidiazuin.blogosfera.uol.com.br/2019/09/02/amazofuturismo-e- 
cyberagreste-por-uma-nova-ficcao-cientifica-brasileira Acesso em 22 de abril de 2021.

Artigo enviado em: 10/05/2021. Aprovado em: 21/06/2021. 